\title{
Studies on the behavior of a new wine grape hybrid elite in the climatic conditions of the Copou-Iasi viticultural center
}

\author{
R. Filimon1, D. Damian', A. Nechita1 and V. R. Filimon1* \\ ${ }^{1}$ Research and Development Station for Viticulture and Oenology Iasi, \\ Romania
}

*Corresponding author email: razvan_f80@yahoo.com

\begin{abstract}
Climatic factors of the ecosystem directly influence the vegetative development of the grapevine, the production obtained, and its quality. Obtaining new genotypes with high ecological plasticity, superior yield and quality, and biological resistance can be achieved by continuously improving the existing assortment of grapevine cultivars. The crossbred of the valuable genitors and the selection of perspective genotypes is a permanent concern of horticultural researchers, in order to satisfy the consumer increasingly selective requirements. The purpose of the current study was to evaluate the adaptation of a new wine hybrid elite ('H.E. 13.1.6') obtained at Research and Development Station for Viticulture and Oenology Iasi to the environmental conditions of the Copou-Iasi viticultural centre (NE of Romania), based on agrobiological and technological observations, and analysis on grape yield and wine quality. The hybrid elite showed high productions (up to $19 \mathrm{t} / \mathrm{ha}$ ), with significant accumulations of sugars in grapes $(>200 \mathrm{~g} / \mathrm{L})$ and high resistance to cryptogamic diseases, indicating a good adaptation to the environmental factors of the growing area.
\end{abstract}

Keywords: agrobiological features, grapevine breeding, hybrid elite, new genotypes, wine grapes.

\section{INTRODUCTION}

Currently, grapevine (Vitis vinifera L.) is cultivated in a relatively small area (7.3 mil. ha), located entirely in areas with a temperate and Mediterranean climate. Most of these areas, about 3.3 million ha, are found in Europe, the rest of the areas are spread over other continents, in the form of individual wine regions. In Romania, viticulture is a traditional occupation, which has evolved due to the favorable climate for grape cultivation. According to the OIV Report for 2020, Romania remains one of the main wine-producing countries in the world, occupying $10^{\text {th }}$ place in terms of area planted with grapevine, respectively 190,000 ha, representing about $2.6 \%$ of the world's wine-growing area. Wine consumption in Romania represents $2 \%$ of world wine consumption.

The viticultural potential is a variable characteristic at the scale of vineyards and viticultural centres. This variability, due to the different influence of ecological factors has determined the appearance of vineyards and their specific type of wine. The wine obtained from grapes of the same cultivar differs from one area to another ( $f r$. terroir), concerning the environmental factors. Moreover, grapevine genotypes behave differently under the influence of climate change, depending on their ability to adapt to higher temperatures and 
drought stress (Creasy and Creasy, 2009). The breeding of the grapevine appeared with its discovery, through the selection of plants with larger and tasty fruits that would satisfy the food need of the consumer. In recent years, many countries have initiated large breeding programs to induce cold, drought, and disease resistance; some important wine grape cultivars were developed from these crosses. Improving the grape assortment is a permanent concern of horticultural researchers. Through advanced breeding programs initiated at the Research and Development Station for Viticulture and Oenology Iasi, more than 20 grapevine cultivars and clones were obtained, aiming the introduction and promotion into the vineyards of new genotypes with superior yield and quality and increased biological resistance. Currently, in the biological fields of the research unit are permanently monitored over 20 new genotypes (hybrid elites and clonal elites), the most valuable being proposed for homologation and promoted in culture. The current study aims to evaluate a perspective hybrid elite 'H.E. 13.1.6' for rose wine, obtained at Research and Development Station for Viticulture and Oenology Iasi (Copou-Iasi wine centre).

\section{MATERIALS AND METHODS}

The study was conducted during the 2019-2020 period, in the experimental plots of Research and Development Station for Viticulture and Oenology Iasi $\left(27^{\circ} 53^{\prime}\right.$ E and $47^{\circ} 20^{\prime}$ $\mathrm{N}$ ), in a microclimate favorable to grapevine growing. The plant material was represented by hybrid elite ('H.E. 13.1.6') for wine grapes, resulting from the crossing of the 'Băbească neagră' × 'Muscat Ottonel' cultivars. Vitis vinifera L. 'Busuioacă de Bohotin' cultivar, with similar technological features and the same production direction (rose aromatic wines), was used as control. The plot was planted at an altitude of $184 \mathrm{~m}$, on a slight slope (3\%) with southern exposition; orientation of rows N-S. The soil is cambic chernozem with a clayloamy texture, $6.8 \mathrm{pH}$ units, $2.7 \%$ humus content, formed on marls with sand insertions, with phreatic water depth at over three meters. The planting distances were $2.2 / 1.2 \mathrm{~m}$, in the semi-high crop system.

The research was focused on observations and determinations regarding the vegetation phenophases, yield and quality, in direct relation to ecological factors. Physico-chemical characteristics of grapes, must and wines were determined according to the OIV methods (OIV, 2016). The biological resistance of the cultivars to the main grapevine diseases was assessed by the means of ampelographic descriptors proposed by OIV (2001). Relative fertility coefficient (RFC), as the ratio between the number of inflorescences and the total number of shoots, and absolute fertility coefficient (AFC), as the ratio between the number of inflorescences and the number of fertile shoots, were calculated. Data were reported as means of two years determinations, with standard deviation $( \pm)$. The coefficient of variation $(\mathrm{CV} \%)$ as the ratio of the standard deviation to the mean was calculated; $\mathrm{CV}<10$ indicates very high data homogeneity.

\section{RESULTS AND DISCUSSIONS}

From 2019 through 2020, the average annual temperatures were higher than the multiannual (30 years) value $\left(9.8^{\circ} \mathrm{C}\right.$ ), reaching $11.6^{\circ} \mathrm{C}$, in 2019 and $12.0^{\circ} \mathrm{C}$, in 2020 . Winter of the year 2019 was thermally normal, the absolute minimum temperature not exceeding $-12.0^{\circ} \mathrm{C}$, without affecting the viability of winter buds. In the Copou - Iasi viticultural center, the year 2019 was considered normal in terms of air temperature and number of precipitations. However, rainfall was unevenly distributed during the vegetation period, with more than $30 \%$ of the annual amount recorded in May and June $(161.6 \mathrm{~mm}$, in 2019; $210.6 \mathrm{~mm}$, in 2020). The year 2019 was classified as dry, with a rainfall deficit, while the 
year 2020 showed values close to the multiannual data $(547.4 \mathrm{~mm})$. High temperatures and rainfall during the vegetation period favored the harmonious development of the foliar apparatus, with a positive influence on the accumulation of sugar and phenolic compounds in grapes. At bud-burst, the rosette is pubescent, light green colored (Figure 1a). The shoot apex is glabrous and the young leaves are yellowish-green with a slightly wavy blade. The shoot is almost glabrous, semi-erect with green internodes and red stripes on the sunny side. The adult leaf is medium-sized, pentagonal, pentalobate, dark green (Figure 1b). The upper lateral sinuses are open, of medium depth, with a lyre-shaped base, and the lower sinuses are shallower, open. The petiolar sinus is open, in the form of an accolade. The teeth are of medium size, with both rectilinear edges. The flower is normal, hermaphrodite, on type five, the cultivar being self-fertile, with the stamens and gynoecium fully developed.

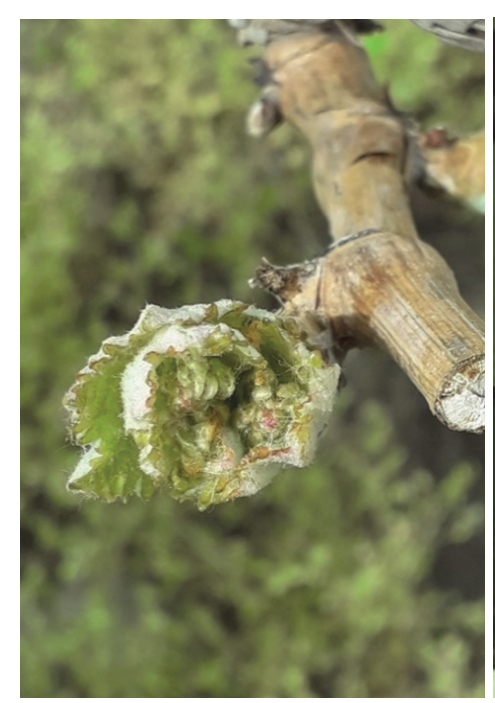

a) Bud burst (EL-5 - rosette of leaf tips visible)

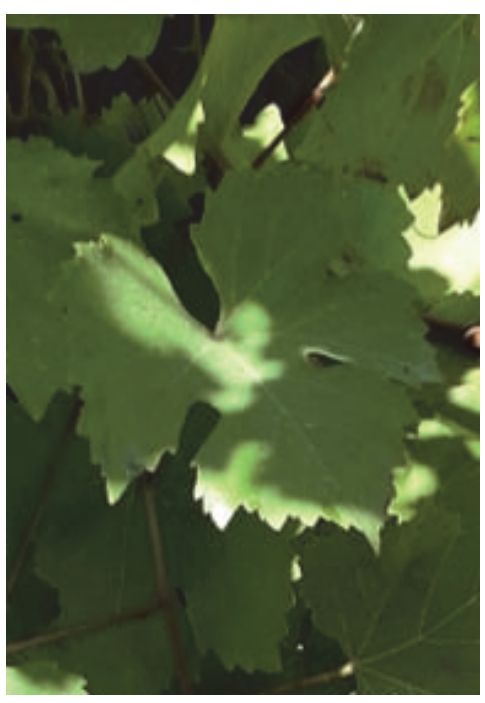

b) Mature leaf

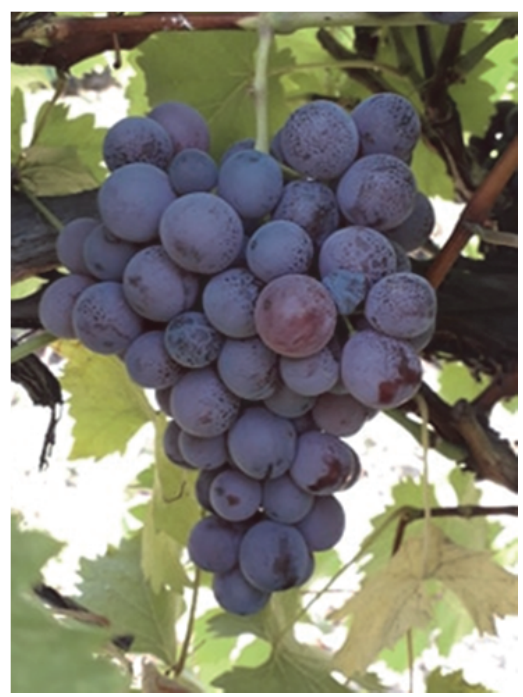

c) Mature grape (EL-38 berries harvest-ripe)

Figure 1. 'Hybrid elite 13.1.6'

Note: EL indicates the grapevine growth stage according to Eichhorn and Lorenz (1977).

The grapes are of conical shape, medium size, and compactness (Figure 1c), with an average length of $140 \mathrm{~mm}$, with variations between 126 and $157 \mathrm{~mm}$. The berries are of smallmedium size, spherical shape, with an average diameter of $12.00 \mathrm{~mm}$ (between 10.4 and $14.2 \mathrm{~mm}$ ), with a dark-red skin, covered with a thin waxy bloom layer. The pulp is juicy, with a pleasant aromatic taste, without anthocyanin coloration. The berries contain on average two seeds.

Under the influence of the climatic conditions specific to the years 2019 and 2020, the bud burst emerged early, between $23^{\text {th }}$ and $27^{\text {th }}$ April, but not earlier than 'Busuioacă de Bohotin' control cultivar (18-25 April) (Table 1).

Table 1. The phenological spectrum of studied genotypes in the conditions of the Copou Iasi viticultural center

\begin{tabular}{|l|c|c|c|c|c|c|c|c|c|}
\hline \multirow{2}{*}{ Genotype } & \multicolumn{2}{|c|}{ Bud burst } & \multicolumn{2}{c|}{ Full bloom } & \multicolumn{2}{c|}{ Veraison } & \multicolumn{2}{c|}{ Grape maturity } \\
\cline { 3 - 10 } & & Date & UTB $\left({ }^{\circ} \mathrm{C}\right)$ & Date & UTB $\left({ }^{\circ} \mathrm{C}\right)$ & Date & UTB $\left({ }^{\circ} \mathrm{C}\right)$ & Date & UTB $\left({ }^{\circ} \mathrm{C}\right)$ \\
\hline $\begin{array}{l}\text { 'Busuioacă de } \\
\text { Bohotin' }\end{array}$ & 2019 & 25.04 & 22.6 & 10.06 & 320.6 & 07.08 & 693.6 & 26.09 & 516.8 \\
\cline { 2 - 10 } & 2020 & 18.04 & 31.6 & 10.06 & 257.3 & 12.08 & 792.6 & 21.09 & 468.6 \\
\hline \multirow{2}{*}{ 'H.E. 13.1.6' } & 2019 & 27.04 & 36.3 & 08.06 & 382.8 & 10.08 & 756.9 & 23.09 & 458.6 \\
\cline { 2 - 10 } & 2020 & 23.04 & 35.2 & 12.06 & 277.5 & 12.08 & 768.8 & 24.09 & 496.0 \\
\hline
\end{tabular}

Note: UTB - useful thermal balance (sum of temperatures $>10^{\circ} \mathrm{C}$ ). 
Flowering started in the first half of June, being conditioned by a useful thermal balance with values between 277.5 and $382.8^{\circ} \mathrm{C}$, and the grape veraison started in the first half of August (10-12 August). The grapes' maturity coincided with the date of harvest and was noted in the second decade of September, in the same period as the control sample. Grape's technological maturity was conditioned by the useful thermal balance, which showed values between 458.6 and $496.0^{\circ} \mathrm{C}$.

The agrobiological characteristics of the 'H.E. 13.1.6' were determined by analyzing the fertility and stress resistance induced by abiotic factors. The fertility of studied genotypes was calculated as the average of the two years data and was ensured statistically by calculating standard deviations and the coefficient of variation. (Table 2).

Table 2. Evaluation of the fertility characteristics of the studied genotypes

\begin{tabular}{|c|c|c|c|c|c|c|}
\hline Genotype & $\begin{array}{c}\text { Number of } \\
\text { shoots/ vine } \\
\text { stock }\end{array}$ & $\begin{array}{c}\text { Fertile } \\
\text { shoots/ } \\
\text { vine stock }\end{array}$ & $\begin{array}{c}\text { Coefficient of } \\
\text { fertile shoots } \\
(\%)\end{array}$ & $\begin{array}{c}\text { Number of } \\
\text { inflorescences }\end{array}$ & \multicolumn{2}{|c|}{$\begin{array}{c}\text { Coefficients of } \\
\text { fertility }\end{array}$} \\
\cline { 5 - 7 } & $36.0 \pm 2.83$ & $23.0 \pm 0.00$ & $64.09 \pm 5.04$ & $26 \pm 1.41$ & $0.73 \pm 0.10$ & $1.13 \pm 0.06$ \\
\hline 'H.E. 13.1.6' & $45.5 \pm 0.71$ & $25.5 \pm 3.54$ & $55.99 \pm 6.90$ & $27 \pm 4.24$ & $0.59 \pm 0.08$ & $1.06 \pm 0.02$ \\
\hline 'Busuioacă de Bohotin' & $40.75 \pm 6.72$ & $24.25 \pm 1.77$ & $60.04 \pm 5.72$ & $26.50 \pm 0.71$ & $0.66 \pm 0.09$ & $1.09 \pm 0.05$ \\
\hline Mean ( \pm CV & 16.48 & 7.29 & 9.54 & 2.67 & 14.29 & 4.72 \\
\hline
\end{tabular}

Note: RFR - relative fertility rate; AFR - absolute fertility rate; CV\% - coefficient of variation.

'H.E. 13.1.6' showed higher fertility $(64.09 \pm 5.04 \%)$ compared to control cultivar $(55.99 \pm 6.90 \%)$. The values of the absolute fertility coefficient (AFC) were also higher at the hybrid elite 13.1.6 than the control variant, the relative coefficient values showing a similar trend. Evaluation of the biological potential of the analyzed genotypes in the climatic conditions of the years 2019-2020, was performed according to the list of OIV descriptors (OIV, 2009), the hybrid elite studied showed very good resistance to frost (winter buds viability was $100 \%)$.

During the vegetation period, when the rainfall was few and unevenly distributed, the studied hybrid elite 'H.E. 13.1.6' showed very high resistance to drought (Table 3), without presenting specific manifestations of water stress (yellowed leaves).

Table 3. Evaluation of the biological potential of the studied genotypes in the Copou Iasi wine center (2019 - 2020) - drought resistance

\begin{tabular}{|l|c|c|}
\hline \multicolumn{1}{|c|}{ Genotype } & Degree of resistance (OIV 403) & Expression code \\
\hline 'H.E. 13.1.6' & 9 & Very good \\
\hline 'Busuioacă de Bohotin' & 9 & Very good \\
\hline
\end{tabular}

After applying eight anticryptogamic treatments during the vegetation period, the studied genotypes showed a good resistance, specific to V. vinifera cultivars (Table 4).

Table 4. The behavior of the studied genotypes at the main diseases of the grapevine

\begin{tabular}{|l|c|c|c|c|c|c|}
\hline \multirow{3}{*}{ Genotype } & \multicolumn{2}{|c|}{$\begin{array}{c}\text { Downy mildew } \\
\text { (Plasmopara viticola) }\end{array}$} & \multicolumn{2}{c|}{$\begin{array}{c}\text { Powdery mildew } \\
\text { (Uncinula necator) }\end{array}$} & \multicolumn{2}{c|}{$\begin{array}{c}\text { Gray mold } \\
\text { (Botrytis cinerea) }\end{array}$} \\
\cline { 2 - 7 } & $\begin{array}{c}\text { Leaf } \\
\text { OIV 452 }\end{array}$ & $\begin{array}{c}\text { Grape } \\
\text { OIV 453 }\end{array}$ & $\begin{array}{c}\text { Leaf } \\
\text { OIV 455 }\end{array}$ & $\begin{array}{c}\text { Grape } \\
\text { OIV 456 }\end{array}$ & $\begin{array}{c}\text { Leaf } \\
\text { OIV 458 }\end{array}$ & $\begin{array}{c}\text { Grape } \\
\text { OIV 459 }\end{array}$ \\
\hline 'H.E. 13.1.6' & 9 & 9 & 9 & 9 & 9 & 9 \\
\hline 'Busuioacă de Bohotin' & 9 & 9 & 9 & 9 & 9 & 9 \\
\hline
\end{tabular}


The powdery mildew and gray mold did not affect 'H.E. 13.1.6', while the pathogen Plasmopara viticola (downy mildew) was slightly present on the grapes of the control variant, without causing significant losses.

The number of clusters per vine stock is directly influenced by the genetic factor, the climatic conditions and also by the agrotechnical measures (Țârdea and Dejeu, 1995). The mean number of clusters per vine stock at 'H.E.13.1.6' was lower than at 'Busuioacă de Bohotin', but the yield per vine stock was positively influenced by the cluster weight (Table 5).

Table 5. The main quantitative characteristics of the studied genotypes

\begin{tabular}{|c|c|c|c|}
\hline Genotype & $\begin{array}{c}\text { Number of } \\
\text { cluster/vine stock }\end{array}$ & $\begin{array}{c}\text { Actual yield (kg/ } \\
\text { vine stock) }\end{array}$ & $\begin{array}{c}\text { Calculated yield } \\
\text { (t/ha) }\end{array}$ \\
\hline 'H.E. 13.1.6' & $24.5 \pm 2.12$ & $5.11 \pm 1.24$ & $19.34 \pm 4.68$ \\
\hline 'Busuioacă de Bohotin' & $26 \pm 2.83$ & $4.56 \pm 0.11$ & $17.28 \pm 0.42$ \\
\hline Mean & $25.25 \pm 1.06$ & $4.83 \pm 0.38$ & $18.31 \pm 1.45$ \\
\hline CV\% & 4.20 & 7.94 & 7.94 \\
\hline
\end{tabular}

Note: CV\% - coefficient of variation.

The average production per vine stock varied between $4.56 \pm 0.11$ and $5.11 \pm 1.24 \mathrm{~kg}$, and the average production calculated per hectare was 19.34 $\pm 4.68 \mathrm{t} /$ ha for the 'H.E.13.1.6', respectively 17.28 \pm 0.42 t/ha for 'Busuioacă de Bohotin'. The hybrid elite 'H.E 13.1.6' showed an increasing yield of about $9 \%$ compared to the control cultivar.

The quality of the grapes, indicated by the average weight of the cluster, the sugar content and total acidity of the must, reflects both the genetic character specific to the cultivar and the influence of climatic factors on these elements. 'Hybrid elite 13.1. 6' was characterized by medium grapes, with an average weight of $207.0 \pm 2.12 \mathrm{~g}$. The weight of 100 berries, was specific to each genotype, ranging from $211.5 \pm 12.02 \mathrm{~g}$ for the control cultivar to $269.5 \pm 3.54$ $\mathrm{g}$ at the 'H.E 13.1.'(Table 6).

Table 6. Quantitative and qualitative characteristics of the studied genotypes

\begin{tabular}{|c|c|c|c|c|c|}
\hline Genotype & $\begin{array}{c}\text { Cluster } \\
\text { weight (g) }\end{array}$ & $\begin{array}{c}\text { Weight of 100 } \\
\text { berries (g) }\end{array}$ & $\begin{array}{c}\text { Sugars } \\
\text { (g/L) }\end{array}$ & $\begin{array}{c}\text { Total acidity } \\
\text { (g/L tartaric } \\
\text { acid) }\end{array}$ & $\begin{array}{c}\text { G.A. } \\
\text { index }\end{array}$ \\
\hline 'H.E. 13.1.6' & $207.00 \pm 2.12$ & $269.50 \pm 3.54$ & $211.00 \pm 1.63$ & $5.29 \pm 0.37$ & 39.88 \\
\hline 'Busuioacă de Bohotin' & $175.50 \pm 14.85$ & $211.50 \pm 12.02$ & $217.50 \pm 1.42$ & $5.69 \pm 0.51$ & 38.22 \\
\hline Mean & $191.25 \pm 22.27$ & $240.50 \pm 41.01$ & $214.25 \pm 4.24$ & $5.49 \pm 0.28$ & 39.05 \\
\hline CV\% & 11.65 & 17.05 & 1.98 & 5.15 & 3.00 \\
\hline
\end{tabular}

Note: G.A. index - glucoacidimetric index (sugar/acidity ratio); CV\% - coefficient of variation.

Due to the low amounts of precipitation and the high temperatures during the grape ripening in the ecopedoclimatic conditions of 2019 - 2020, the studied elite showed high and constant sugar accumulations $(211 \pm 1.63 \mathrm{~g} / \mathrm{L})$. The total acidity of the grape must be within normal limits, between $5.29 \pm 0.37$ at the hybrid elite 'H.E. 13.1 .6 ' and $5.69 \pm 0.51 \mathrm{~g} / \mathrm{L}$ tartaric acid at the control variant.

Grape ripening is a very complex biochemical process. To assess the degree of grape ripeness the glucoacidimetric index is determined, as the ratio between the total sugar content and total acidity. For wine grape cultivars, the desirable values of the glucoacidimetric index are between 27 and 34, depending on the cultivar. Between these limits, grapes reach the optimal degree of maturation that ensures the production of quality wines (Grumezescu and Holban, 2019). Both 'H.E. 13.1.6' and the control cultivar showed high values of the glucoacidimetric index (38-39), which ensures the obtaining of quality wines. The wines obtained from the grapes of studied genotypes, by the classic winemaking 
process (crushing-destemming), showed alcohol concentrations between 12.20 and $12.50 \%$ vol., a balanced total acidity (4.46-4.87 g/L tartaric acid), which provides the wine freshness, and small amounts of residual sugars (dry wines), (Table 7).

Table 7. Main chemical characteristics of the wines of studied genotypes

\begin{tabular}{|l|c|c|c|c|c|c|c|c|}
\hline Genotype & $\begin{array}{c}\text { Alcohol } \\
\text { (\% vol.) }\end{array}$ & $\begin{array}{c}\text { TA (g/L } \\
\text { tartaric } \\
\text { acid) }\end{array}$ & $\begin{array}{c}\text { VA (g/L } \\
\text { acetic } \\
\text { acid) }\end{array}$ & $\begin{array}{c}\text { Free } \\
\mathrm{SO}_{2} \\
(\mathrm{mg} / \mathrm{l})\end{array}$ & $\begin{array}{c}\text { Reducing } \\
\text { sugars } \\
\text { (g/L) }\end{array}$ & pH & $\begin{array}{c}\text { TPC } \\
\text { (g GAE/L) }\end{array}$ & $\begin{array}{c}\text { Ant. } \\
\text { (mg/L) }\end{array}$ \\
\hline 'H.E. 13.1.6' & 12.20 & 4.46 & 0.32 & 28 & 1.02 & 3.59 & 0.86 & 175.20 \\
\hline 'Busuioacă de Bohotin' & 12.50 & 4.87 & 0.38 & 84 & 1.24 & 3.48 & 0.89 & 184.16 \\
\hline
\end{tabular}

Note: T.A. - titratable acidity; VA - Volatile acidity; GAE - gallic acid equivalent; Ant. - anthocyanins.

The volatile acidity of the wines was low (0.32-0.38 g/L acetic acid), with low concentrations of $\mathrm{SO}_{2}$ being required to ensure the antioxidant stability of wines. The content of phenolic compounds, determined spectrophotometrically with the FolinCiocâlteu reagent, was medium (0.86-0.89 $\mathrm{g}$ acid gallic/L), the presence of anthocyanins in high concentrations (175.20-184.16 $\mathrm{mg} / \mathrm{L}$ ) offering the possibility of obtaining high quality rose wines.

\section{CONCLUSIONS}

The climatic conditions of the reference years positively influenced the development of the Hybrid elite 'H.E. 13.1.6' and 'Busuioacă de Bohotin' control cultivar, favoring grape ripening and the accumulation of sugars.

Hybrid elite 'H.E.13.1.6' was characterized by medium grapes (207.0 g), with a specific flavor and high grape yield (19.34 t/ha), being over $9 \%$ more productive compared to the control ('Busuioacă de Bohotin').

The elite 'H.E. 13.1.6' showed high ecological plasticity, high quality productions, good resistance to frost, drought, and cryptogamic diseases, characteristics that recommend its introduction in the assortment of grapevine cultivars recommended for quality rose wines in the temperate climate area.

\section{ACKNOWLEDGEMENTS}

This study is part of MADR research program ADER 2019-2022, Project no. 7.2.3/2019 "Valorisation of the local viticultural germplasm by creating new cultivars of vines with superior quantitative and qualitative potential, with genetic resistance to diseases and stress factors".

\section{REFERENCES}

1. Creasy G. L. and Creasy L. L. (2009). Grapes. CAB International, UK.

2. Eichhorn K.W., Lorenz D.H. (1977). Phänologische entwicklungsstadien der rebe. Nachrichtenbl. Deut. Pflanzenschutz., vol. 29, pp. 119-120.

3. Grumezescu A. And Holban A. M. (2019). Fermented Beverages: Volume 5. The Science of Beverages. Elsevier, UK. p. 151.

4. OIV (2009). The $2^{\text {nd }}$ edition of the OIV Descriptor list for grape cultivars and Vitis species. International Organization of Vine and Wine, Paris, France. Available online at: https://www.oiv.int/public/medias /2274/code-2e-edition-finale.pdf.

5. OIV (2016). Compendium of international methods of wine and must analysis. Vol. I. International Organisation of Vine and Wine, Paris, France.

6. OIV (2020). Statistical Report on World Vitiviniculture. International Organisation of Vine and Wine, Paris.

7. Ţârdea C. and Dejeu L. (1995). Viticulture. Editure Didactică și Pedagogică, Bucharest, Romania. 